\title{
A RECOVERY JOURNEY FOR PEOPLE WITH PERSONALITY DISORDER
}

\author{
Accepted for publication by the International Journal of Social Psychiatry $\left(15^{\text {th }}\right.$ \\ November 2012) \\ Heather Castillo, Shulamit Ramon and Nicola Morant
}

\begin{abstract}
Background: The study investigates the process of recovery for people diagnosed with personality disorder, a client group that suffers significant social exclusion known to impact on demand for health and other public services. It aims to examine efforts which attempt to reverse this social exclusion as an aspect of the recovery process.
\end{abstract}

Aim and Method: The following study aims to i) explore what recovery means to people with personality disorder ii) develop a conceptual model of recovery in personality disorder iii) evaluate the contribution of the setting (The Haven) to recovery practice. The study uses a PAR (Participatory Action Research) design. Data was collected from 66 participants by focus groups and individual interviews.

Findings: A map based on thematic analysis of data collected during the study is proposed of the recovery journey for people with this diagnosis, shown as a pyramid which represents a hierarchy of progress from building trust through stages of recovery to social inclusion.

Conclusion: Findings offer contributions to knowledge in terms of the service design and propose a new model of recovery in personality disorder. This is defined as a journey of small steps highlighting recovery as a process rather than a goal, leading to the emergence of the new concept of Transitional Recovery.

Key Words: Personality Disorder; Recovery; Transitional Recovery; Social Inclusion; Mental Health Services. 


\section{INTRODUCTION}

The Haven is the service setting for the research reported in this paper. It began in 2004 as a service model coming out of previous user involved research (Castillo 2003; Ramon et al 2001). It arose in a climate where pilot services for personality disorder were being proposed nationally by the Department of Health. Uniquely, it was created as a blend of models combining a therapeutic community with a crisis house. Faulkner et al (2002) championed the efficacy of the crisis house model, highlighting the user-led nature of such services and the emphasis on human interaction rather than drug treatments. The Haven aspires to be a sanctuary with a sense of home which is a place of refuge and protection (Bloom 1997). It is housed in an old Rectory in Colchester and its décor is warm and inviting. The services offered include a therapy and group programme, 24 hour crisis phone and text lines, a Safe Centre where those in crisis may come, at any time of the day or night, and four bedrooms constituting a Crisis unit.

\section{DEFINING RECOVERY}

The word recovery has a range of meanings, suggesting that conceptual clarity is necessary. Slade et al (2008) identify two classes of meanings. First is the traditional concept of recovery as cure. This locates the concept within an illness framework. Second is the personal definition of recovery, which has emerged from service user narratives. These accounts emphasise the understanding of recovery as something other than the absence of mental illness. Davidson (2003) defines recovery as living well with the illness and beyond the illness. Recovery requires hope and opportunity. It is about building a future and recovering social roles and relationships that give value to life.

Recovery as a clinical concept, measured in out-come studies as an approximation of cure, may be considered an imposition upon people struggling with serious and painful conditions as an unrealistic expectation and a burden to get well. Wallcraft (2005) considers that concerns, fears and objections to recovery will best be overcome by ensuring that it is a philosophy for life that becomes owned and defined by service users 
and survivors, and that this ownership must be respected by politicians, planners and service providers. Wallcraft (2005), Coleman (1999) and Deegan (1996), writing from the perspective of service users activists, see recovery as a process rather than a goal. Therefore recovery might best be defined as The Journey of Recovery. A sixteen year study, of a large sample with borderline personality disorder, was carried out by Zanarini et al (2012) who concluded that remission of symptoms is more common than full recovery. Turner et al (2011) highlight the complexity of the recovery debate and how it has travelled a long way from its roots in the survivor movement. Here the emphasis for service users has become one of self-discovery rather than recovery. They consider that the notion of recovery is a concept hijacked by mainstream services in a way which is unrealistic because it fails to acknowledge the challenges of living with the ongoing, painful legacy of trauma.

Nehls (2000) suggests that, although advances have been made, psychological approaches developed in treating personality disorder are not consistent with the concept of recovery as a vision constructed by the client, and that a new vision of treatment, based on recovery, will require a fundamental shift in control from professionals to the person who is recovering. Katsakou et al (2012) concluded in their study of recovery in borderline personality disorder, that professionals needed to devise more individualised treatment targets and outcomes which would include priorities important to service users. Therefore, it has been important in this study to examine the underpinning values, in the field of mental health, in relation to the possibility of recovery, to identify the important factors in recovery for those diagnosed with personality disorder, and to ensure that the concept is defined or redefined by them. There is an assumption in recovery oriented care, that professionals and clients will pursue client-oriented goals together, but decisions about what services are delivered are usually controlled by providers. Roberts and Wolfson (2004) suggest that, in contrast with a patient struggling for cure, recovery depends much more on collaboration than on treatment. However, the skills, knowledge and commitment that professionals can bring to the recovery process, while valuing and learning from the client, are important too. They emphasise the need to develop research methods that will incorporate subjective accounts of recovery, from service users, in 
order to better inform professionals and suggest that professionals will find little guidance about what might help recovery from a randomized controlled trial.

\section{AIMS AND APPROACH}

The aim of the study was to find answers to the following questions:

- How do those with a personality disorder diagnosis define recovery?

- What factors are important in the recovery process for those with personality disorder?

- Does The Haven, as a service, contribute to this process, and if so how?

The research approach was empancipatory where the study of a problematic or oppressive reality is not carried out by experts but primarily by those experiencing the problem (Freire 1970). Here, service users became researchers in the study with control over the selection of issues to be researched, data collection, analysis and dissemination (Ramon 2003).

\section{METHOD}

The study used a PAR (Participatory Action Research) framework which enabled cycles of action and reflection (Reason and Bradbury 2001). The core issue underpinning its action research nature was to bring about change in the direction chosen by participants.

The Research Group, with a membership of nine Haven clients and the Chief Executive, was a primary vehicle in this process. The intention to create a group was made known to clients by advertising with posters and mailings. The membership of the group was by self-selection and this yielded participants who were particularly committed to the research task. Most maintained their membership in the group for five years. Preparation for the research task became a necessary part of group activity. Methods employed for data collection included not only focus groups and individual interviews but background data used to inform and illustrate results, combining data streams representing a rich amount of information. 


\section{Sampling and Participants}

The potential sample for the study included 166 clients registered at the service by the time the study was complete in 2009 , and any associated family members and carers. The 66 participants involved in the study began to be identified by self-selection achieved by posters and mailings about the research, and the ready availability of information sheets and consent forms at the service. This opened up attendance at focus groups and individual interviews to all registered clients. This was followed by a degree of purposive sampling. Consideration was given to age, gender, domiciliary situation, marital status, parenthood, education and presenting problems, aiming to broadly reflect the overall population of Haven clients (see Table 1). Sampling was primarily aimed at ensuring the capture of the diversity of the population studied and its likely opinions. For example, people who left the service in unsatisfactory circumstances were encouraged to participate. Other participants were invited because of their comprehensive use of various parts of the service or because of marked positive change in terms of coping strategies. Demographic and other details regarding the sample follow (see Table 1).

(Table One)

\section{Data Collection}

The methods of data collection included focus groups and individual interviews. Focus groups were one and a half hours in length and individual interviews took approximately one hour. The Research Group was a prime mover in this process. The group was formed in June 2004 and met 35 times until September 2009. The group selected one of its members to act as the focus group facilitator and service user interviewer. Having a service user as the interviewer, and not a staff member, was another way of encouraging freedom of expression. The Research Group considered that the perspectives of carers and family members were also an important comparison with the views of clients and, for this reason, two carer focus Groups were held and participants for this were elicited by self-selection from a broad mailing to family and friends. Again freedom of expression was strengthened by inviting a carer from outside of the service to lead the carers' focus 
group. The data collection process began in February 2005 and ended in November 2007, during which time 14 group events were held and 20 individual interviews were conducted.

\section{Data Analysis}

By the end of data collection, in November 2007, 770 pages of verbatim transcripts had amassed. Data analysis took one and a half years. The Research Group, consistent with our PAR framework, continued to be as crucially involved in data analysis as they were in data collection. They agreed that it was very important to see the breakdown of responses to questions, in terms of their themes and also their incidences. Thematic analysis was the method used for data analysis. This was a way of identifying and analysing patterns within data rich in detail and searching for themes across the entire data set (Braun and Clarke 2006). NVivo software system was used to support this process.

\section{FINDINGS}

Whilst data collection and analysis was occurring, a range of background data was also collected at the service for our funders. By 2006, an analysis of use of the wider service area, for the first 50 Haven clients who had been with the project for one year, showed a drop in use of all services measured (see Table 2). Notably, psychiatric hospital inpatient admissions had dropped for the first 50 clients by $85 \%$.

(Table Two)

The North Essex Mental Health Trust updated this chart in 2009, suggesting that the average annual reduction in the use of their services had been maintained over a four year period (see Table 3).

(Table Three)

Calculating the reduction of the use of the wider service area against health and social care figures, in national tariff documents, showed that the project had saved $£ 220,000$ per annum, over and above the cost of The Haven, for the first 50 clients. We had by then 
registered 110 clients, and extrapolating savings to this number showed that in excess of $£ 480,000$ per annum could be saved. The cost per week, per client, for Haven services was around $£ 100$, compared to costs ranging from $£ 223$ to $£ 1,250$ per patient per week, for personality disorder day unit or hospital therapeutic community, in other parts of the country (Chiesa et al 2002).

The Haven had fulfilled its original promise to engage the client group in our area and to produce cost savings in the wider service sector. However, concerns began to be expressed about whether the project would create a new kind of dependency. Most of Haven clients were no longer subject to hospital admission but questions were asked about whether they could move beyond stability achieved at The Haven. Answers to these questions are described later in relation to the research findings.

\section{Mapping the process of recovery}

Findings from the groups and interviews in the research transcripts, together with all data collected during the study, had been subject to thematic analysis. An examination of emerging themes within and between transcripts and questions, and the interplay between themes, gives insight into what respondents consider to be the key steps in the journey of

recovery for someone with a personality disorder diagnosis. All theoretical frameworks carry a number of assumptions about the data and a good thematic analysis makes this transparent, therefore, the process of searching for themes, reviewing themes, defining and naming those themes and the way in which they relate and fit together to represent a sequential journey, was a lengthy and exacting task. Themes are initially presented diagrammatically, below, as a pyramid representing a hierarchy of progress.

Maslow's (1943) pyramid of the Hierarchy of Needs is a guide to the growth of an organism and a well-lived life. Although there are differences which reflect the specific needs of those with the diagnosis of personality disorder, this concept has been used as a template which lends itself to the journey and growth experienced by our participants. The journey might have been represented as a chart, reading from left to right, or a stairway climbing upwards. However, the concept of a Maslow-type pyramid captured 
the imagination and was considered to be inspirational by the Research Group because it seemed to ideally represent a personal journey of growth.

Each level of the pyramid is discussed in sequence, from the base upwards, and this represents a synthesis of the recovery concept, as a way of understanding the process of recovery for people with a personality disorder diagnosis.

\section{(Diagram 1)}

\section{A sense of safety and building trust}

Basic trust is associated with secure attachment. Campling (1999) proposes that severe personality disorder is related to insecure and disorganised attachment, where an infant may freeze on separation and be unable to sustain organised patterns of behaviour. She suggests that such experiences yield a future generation of people with personality disorder. Therefore, in working with someone who has a personality disorder diagnosis, trust has to be created in a very tangible way. The first lesson in our study was that participants were able to define the component parts of a safe place and how this related to an increased ability to protect them from the harm they might do to themselves:

You can feel it when you walk in that door, you can feel that safety. It's a safe place. It helps you to be safe.

The 24 hour nature of the service emerged as a crucial factor that could be internalised, even when not physically present at the service.

It makes me feel very safe and secure to know it's always there. To me it's safe 24/7, it's a haven.

Feeling safe was related to learning to trust, and trusting meant that it was safe to show one's pain and talk about difficult emotions and experiences:

The Haven has taught me to trust again. I don't have to hide behind a smile anymore. I can come in and cry. The important thing is that coming here makes you safe enough to change.

The perspectives of family members emphasised the importance of safety and trust: 
It's helped my daughter. It's somewhere safe for her to come, somewhere without any bad memories.

I knew that I could probably go to sleep and that he was going to be okay and safe.

\section{Feeling cared for and creating a culture of warmth}

The study also revealed the importance of feeling cared for as a finding and participants described care in terms of first contact and acceptance. They knew about the affection that can exude from a smile and the warmth than can be felt from a hug or simply being made a cup of tea:

They always look pleased to see you coming through the door.

It's been excellent, a kind ear, a cuddle, cup of tea, respite when I need it.

They spoke of being listened to and treated as being important, and of interconnectedness and humanness:

As a family member, I have to say that I just think The Haven is just a calm, happy, just a caring place. To be honest I found the hospital a hustle and bustle, and just total chaos.

\section{A sense of belonging and community}

Secure early attachment gives an infant a consistent experience of existence, which is internalised and provides a greater ability to face later life experiences (Bowlby 1969). When emotional development has not provided secure attachment for a child, the first step in treatment is to recreate a secure attachment (Haigh 1999). Our families are supposed to provide a place in which we feel safe and learn to trust. Clients at The Haven had often found this not to be the case and they came to us instead with a legacy of abuse, neglect, abandonment or a lack of emotional responsiveness. The next finding 
to emerge from the study was about the sense of belonging that the community generated. This was experienced as a reciprocal relationship where common ground was identified:

I isolate and can't mix with people, but I can see people in The Haven, you are the same as me.

Where decision making was shared, bonds of friendship were made, where there was fun, where shared realities were negotiated, where there were experiences of uniting in a common purpose:

It's all about human contact. I think a lot of people here realise what it's like to be lonely, we all know what it's like so we all make an extra effort to be friendly.

Winnicott (1965) suggests that a facilitating environment acts as a container where the gap between the container and the contained starts to open up and the individual can begin to explore autonomous identity:

What I have found is that other people can like me. I am less serious. I have rediscovered my sense of humour and I have rediscovered my ability to make other people laugh. I rediscovered the fact I am good.

Voicing their newly developed sense of healthy attachment, participants began to regain, or gain for the first time, a sense of home and family:

It's like having a family all under one roof.

It's the family I never had.

Negative aspects of community were also expressed by some as a sense of alienation engendered by seeing others making friendships and joining in:

Sometimes I do feel alone at the groups.

I struggle with this idea of community. Sometimes I feel very, very threatened and vulnerable. 


\section{Learning the boundaries - love is not enough}

For someone who has experienced early attachment difficulties, healthy attachment may be longed-for but also feared. The concept of attachment becomes idealised as an individual yearns for unconditional love. Haigh (1999) describes this process as a journey through the developmental phases of attachment in a therapeutic community. As an individual struggles with sadness, fear, pain and anger, savage mechanisms can sometimes come into play. The ability to be honest may be blocked by feelings of shame and humiliation. Here, denial, lying, projection and splitting begin to be demonstrated. Someone may display unconscious impulses to envy, spoil, steal or destroy what is good. Family member participants set the scene with some of their observations about behaviours:

She was stoned on Wednesday before we turned up. I'm also aware she's sold drugs, I caught her out at Christmas time drug dealing to children.

She tried to kill herself desperately under the care of the hospital and previous regimes.

Living too long with untenable emotions and in a state of chronic hyper-arousal, people with a personality disorder diagnosis frequently adopt dysfunctional behaviours to numb unbearable feelings and to swiftly bring their mood down to a manageable level. Hurting the body can create temporary calm because of endorphin release. Such behaviours include self-harm and substance misuse. This is how people have coped and, for many, these become deeply ingrained coping strategies. Although containment is achieved through holding someone's distress, that distress may trigger unacceptable behaviours. Bettleheim (1950) suggests that 'love is not enough' and that the damaging expression of pain needs containing measures.

All this represents boundary setting and the social and moral limits that need to be present, clear and known to create a safe community. The Haven's Acceptable Behaviour Policy was created in collaboration with its clients and is administered by the clients. If a Haven Community Member breaks the rules laid out in this policy there are consequences, and that client will be invited to a Community Discussion with peers if a 
boundary has been clearly transgressed. Rules include issues such as self-harm, overdosing, substance misuse and disruptive or anti-social behaviour. Decisions at Community Discussions might involve making an apology, having a contract drawn up, or exclusion with telephone support:

I feel safe at The Haven because I know you're not allowed to get away with stuff like cutting while you're here, which means I don't try. It's about being protected from the negative parts of yourself.

The process of democratically setting and applying boundaries is cited by Hinshelwood (1996) as a learning process which addresses respect, not just for the reality of self, but also for the reality of others, enabling an individual to take control and responsibility:

We understand why people want to come in, for example, under the influence. We understand the struggle and the difficulties but we have, on those occasions, stood together as a community and we have said 'this is unacceptable'. People aren't abandoned at such difficult times, but the learning is about what is acceptable and unacceptable to the community and what is healthy and positive for the individual. We all take responsibility for The Haven Community but, at the end of the day, the message is that each person has to take responsibility for themselves, with our support.

Evidencing the efficacy of Learning the Boundaries, over two-thirds of participants in the study reported a reduction in their use of negative coping strategies and over one-third described a dramatic reduction:

Before I came to The Haven I used to overdose on a reasonably regular basis, I used to cut myself when anything went wrong, and I used to stop eating when anything went wrong. Basically, it was a whole host of maladaptive coping mechanisms and since coming to The Haven I have sort of redressed these. A lot of the reason has been because of the ruling about coming in when you have cut, or coming in when you have drunk alcohol.

The first four findings have concerned developing healthy attachment in terms of safety and trust; feeling cared for, a sense of belonging and learning acceptable boundaries, limits and behaviour. The next finding revealed that only when these were in place, and sufficiently consolidated, did respondents begin to learn to contain their past experiences 
and build necessary skills to progress. Meaningful therapy can not take place, no matter how desperately it is needed, if trust does not exist and if behaviour is chaotic, risky and destructive.

Before I came to The Haven nearly every other day I was tying things around my neck, overdosing, cutting myself and since coming to The Haven I don't tie anything round my neck, I've had maybe one overdose and I've learned to talk and, when things get really bad, to phone and ask for support instead of acting on impulsive thoughts.

The finding that second-stage progress for clients relies on the lessons of the first four levels provides answers as to why someone with a personality disorder diagnosis may be progressing, or why this may not be the case.

\section{Containing experiences and developing skills}

Recreating healthy attachment opens the door to therapeutic work. Healing is about integrating experience by making sense of what has happened. Prior to this stage, reality has often proved to be unbearable and making sense out of traumatic experiences and child abuse is a difficult thing to do. This finding marked the long process of beginning to reframe traumatic experience:

I had ten years of psychotherapy and I still managed to avoid the issues. With the counselling I think it's the fact that it's here. It makes me feel safer which makes me take more risks than I ever have.

I'm clean and have stayed clean. Kind of like instead of popping a pill, I come here. Stopping drugs, feeling the emotion and learning from it.

Participants also began to express a new ability to mentalize; to separate out from their mental processes, achieve objectivity, and reflect on them (Bateman and Fonagy 2004).

I think my new skills have fundamentally been to be able to stop and question the reality of the situation, and to think the whole situation through, rather than jump into the first panic stricken thought that comes into my head and act on it. It's the actual stopping and analysing the situation for what it really is, not what emotionally it's built itself up to be. 


\section{Hopes, dreams and goals and their relationship to recovery}

Although dealing with symptoms and developing skills had an important place in the journey, they were not an underpinning principle in the user defined concept of recovery. Waiting until all symptoms have subsided, before trying to discover and use one's abilities, could take a very long time and hope for a cure can overtake other ambitions.

We can only learn to live alongside our illnesses by re-thinking the way we think, to re-train the way we go about our daily lives and to learn to use our past experiences to guide us to were we want to be in life rather than carrying on the way we do.

A focus on a deficit in skills can create a sense of hopelessness which is a feeling easily triggered in the face of past trauma. Deegan (1990) characterises this 'giving-up', indifference and apathy as a way of surviving and protecting the last vestiges of the wounded self:

Things that have happened to me when I was in care and on the streets ... the world I was in before was so black, and that was hard, I was petrified of becoming well and then failing every time, failing myself again.

A sense of hope and realistic, attainable dreams and goals emerged as the next finding. Hope is a mysterious thing in that it can transcend life's catastrophes. Here some participants said they had begun to conceive of dreams and goals for the first time:

Before The Haven I wanted to die. Now I want to live.

I look to the future more than I ever did. It exists now.

My goal is to get through college and do my degree.

\section{Achievements, identity and roles}

What respondents felt they had accomplished emerged as a finding about achievements.

This included both internal and external achievements. This interplay between the development of personal qualities, such as confidence and self-esteem, and their external expression, characterised their responses. Beginning from what was usually a high degree of self-loathing, during the course of the study $75 \%$ of client participants 
answering a question about their internal sense-of-self reported positively, regarding disliking oneself less. The majority who answered positively had been attending The Haven for two to three years, suggesting that building self-esteem, even in a hopeinspiring environment, takes time:

I don't actually dislike myself now, although I dislike my behaviour at times, which is a massive difference and I'm actually able to go out and buy new clothes.

Although there are still good days and bad days, if you learn to love yourself you can begin to help others.

The remaining $25 \%$ of participants, who answered 'no', included some who had not been long in attendance at the service, however, for $6.6 \%$ of participants, who had been at The Haven for two to three years, although other improvements had occurred, this did not yet include achieving a change in their internal sense of self:

I still dislike myself. I don't know if it will ever change, it's always as far as I can remember for such a long time ago, that's just how I feel about myself.

Participants spoke of external achievements in terms of homemaking, parenting, leisure activities, education, voluntary work and employment, and how these achievements had given them a role and contributed to growing confidence:

The change is due to actually learning who I am. I've been something else before now.

One of the biggest new skills I'm learning is how to be a Mum, how to be patient, how to interact with someone who can't talk, and to love someone who's so dependent on you, learning to love you could say.

Before I came to The Haven I was locked up in a secure unit. I used to wake up every day wanting to die, trying to find a way to actually harm myself, to actually end it all, and now I'm actually going to college.

I'm actually working now and earning a reasonable amount of money. Working gives me a sense of purpose. It's very easy to slide into the diagnosis and not try to do anything. Although it has been so difficult, my self-esteem and confidence have risen massively. 
Fifteen percent of Haven clients are engaged in paid employment or permitted work, which is much higher than the national average of $3.4 \%$ for people with mental health problems (HM Government 2009). Employment may be a highly valued goal by both professionals and service users; however, it is not for everyone and a job that is not right for someone may even undermine recovery.

\section{Transitional recovery and how to maintain healthy attachment}

Transitional Recovery emerged as both a concept and a vehicle. It embraces all other findings in that clients can continue their journey of recovery by defining and pursuing their unique goals and dreams, whilst still having a choice about whether to remain registered at The Haven or not. Participants feared losing their secure attachment and sense of home if they recovered. Many respondents had not developed a safe base in life and had no family or wider network of support to turn to if necessary. Some had achieved this at The Haven for the first time in their lives:

When I think of recovery I get very frightened because I think recovery is like being on the top of a mountain and if I've recovered it means that I won't need The Haven anymore, and I cannot imagine having no more contact with The Haven.

One of my first questions when I very first came here, I said, is this a conveyor belt to chuck us in and chuck us out, get us well, I said, or is this a firm base that stays here forever? Just hold my hand on my bad days.

Because the word recovery could potentially become synonymous with the idea of loss, and the pursuit of recovery could lead to the withdrawal of crucial support, it became vital to define what came next in a way that was going to work. As a result, the concept of Transitional Recovery was born, meaning that progress would be defined as a journey of small steps and that progression would not be penalised by discharge but rather rewarded by continued support, resulting in less use of the service over time but a choice about whether to remain part of it:

I don't think we should clip our wings, we just need a nest to come back to.

If you feel well rooted then, like a tree, you can kind of branch out and blossom. 
The vehicle of implementing Transitional Recovery became the Social Inclusion Unit at the service, where clients are able to work specifically on personal development skills related to their aspirations and achievements outside of The Haven.

However, the notion of the word 'recovery' readily translates to professionals, welfare benefits agencies, commissioners, and the world, as an expectation that people will be well, stable and no longer in need of long-term care. Fundamental vulnerabilities are overlooked (Turner et al 2011) and, unwittingly, despite its transitional recovery ethos, and by its very invitation to dare to hope, The Haven is likely to have contributed to what Scanlon and Adlam (2011) would describe as unacceptable invitations to those who are socially excluded that may deny the complexity and chronicity of some of their problems.

\section{CONCLUSION}

The Haven has emerged as a unique model where therapeutic community principles have been combined with a crisis unit. The entire structure of the service at The Haven has been suggested and refined by its service users. They have had, and continue to have, a fundamental role in how the service runs and develops. Their unique knowledge about what would best help them to progress has shown that crisis support, therapy services and social inclusion development can all co-exist in a very effective way, as a continuum of support under one roof. This shows that it is possible to work effectively with a relatively large number of people with personality disorder, well in excess of a hundred at one time, many of whom had not made progress in other service settings, resulting in significant financial savings to the health, social care and criminal justice system.

This study has begun to create a synthesis of human development and recovery theory, which is new and important for people with a personality disorder diagnosis. What is unique about this study is that the significances of the recovery journey in personality disorder have been defined by service users. As such, our findings focus on the experiences and perspectives of service users and carers, a form of evidence that is not easily captured by positivist methods such as randomized controlled trials. 
We accept that the positioning of the first author as Chief Executive of The Haven, as well as the make-up of the Research Group, may have shaped the data collection and analysis processes, although we made every attempted to mitigate the impact of this through a reflexive and collaborative approach to data analysis.

We additionally acknowledge a limitation in the study, which also constitutes a limitation in The Haven service, in that therapeutic communities may not work for everyone. A minority felt alienated by the sense of community and others were not ready or able to adhere to the boundaries of the service. Opinions of such clients were not always captured because they may not have participated in the research endeavour as their trust was too low to do so. The sense of betrayal can run so deep that efforts to help are interpreted as harm and a fundamental lack of trust gives little chance of someone being able to learn the boundaries of acceptable behaviour.

For those for whom The Haven has worked, as an alternative to the historically sequential path of rehabilitation and proposed recovery, the service offers a new, socially inclusive way of working with people who have a personality disorder diagnosis where they may choose to retain a haven while continuing to develop and progress on their chosen path in the wider world. If we are not to lose the essence of what service users in this study have to say, we must be open to the realism of the ongoing challenges, both the successes and the setbacks, attached to the journey of those who have attracted a diagnosis of personality disorder. 


\section{REFERENCES}

Bateman, W.B. and Fonagy, P. (2004) Mentalization-Based Treatment of BPD. Journal of Personality Disorders, 18(1), pp. 36 - 51.

Bettleheim, B. (1950) Love Is Not Enough. New York: The Free Press.

Bloom, S. (1997) Creating Sanctuary: Towards the evolution of sane societies. New York: Routledge.

Bowlby, J. (1969) Attachment and Loss. London: Hogarth Press.

Braun, V. \& Clarke, V. (2006) Using thematic analysis in psychology. Qualitative Research in Psychology, 3, pp77-101.

Campling, P. (1999) Chaotic Personalities: Maintaining the Therapeutic Alliance (in Campling, P. \& Haigh, R., 1999, Therapeutic Communities: Past, Present and Future. London: Jessica Kingsley.)

Castillo, H. (2003) Personality Disorder: Temperament or Trauma? London: Jessica Kingsley Publishers.

Chiesa, M., Bateman, A., Wilberg, T. \& Friss, S. (2002) Patients' characteristics, outcome and cost-benefit of hospital-based-treatment for patients with a personality disorder: A comparison of three difference programmes. Psychology and Psychotherapy: Theory, Research and Practice, 75, pp381-392: The British Psychological Society.

Coleman, R. (1999) Recovery: An Alien Concept? Gloucester: Handsell.

Davidson, L. (2003) Living Outside Mental Illness: Qualitative Studies in Schizophrenia. New York and London: New York University Press.

Deegan, P.E. (1990) How recovery begins. The Centre for Community Change Through Housing and Support: VT, CI 25: Burlington: Trinity College.

Deegan, P.E. (1996) Recovery as a Journey of the Heart. Psychiatric Rehabilitation Journal 19, 3, p. 91 - 97.

Faulkner, A., Petit-Zeman, S., Sherlock, J. \& Wallcraft, J. (2002) Being There in a Crisis. Mental Health Foundation and Sainsbury Centre for Mental Health.

Freire, P. (1970) Pedagogy of the Oppressed. New York: Herder and Herder.

Haigh, R. (1999) The Quintessence of a Therapeutic Environment: Five Universal Qualities (in Campling, P. and Haigh, R., 1999, Therapeutic Communities: Past, Present and Future. London: Jessica Kingsley.) 
Hinshelwood, R. D. (1996) Communities and their health. Therapeutic Communities, 17, pp173-182.

HM Government (2009) Work Recovery and Inclusion: Employment support for people in contact with secondary mental health services.

Katasakou, C., Marougka, S., Barnicot, K., Savill, M., White, H., Lockwood, K. \& Priebe, S. (2012) Recovery in Borderline Personality Disorder (BPD): A Qualitative Study of Service Users' Perspectives. PloS ONE, 7, 5.

Maslow, A.H. (1943) A Theory of Human Motivation. Psychological Review 50, 4, pp370-96.

Ramon, S., Castillo, H. \& Morant, N. (2001) Experiencing Personality Disorder: International Journal of Social Psychiatry, 47, 4, pp1-15.

Ramon, S. (2003) Users Researching Health and Social Care: An Empowering Agenda? Birmingham: Ventura.

Reason, P. \& Bradbury, H. (2001) Handbook of Action Research. London: Sage.

Roberts, G. and Wolfson, P. (2004) The rediscovery of recovery: open to all: Advances in Psychiatric Treatment, Vol 10, pp37-49.

Scanlon, C, \& Adllam, J. (2011) Cosmopolitan minds and metropolitan societies: Social exclusion and social refusal revisited. Psychodynamic Practice, 17, 3.

Slade, M., Amering, M. \& Oades, L. (2008) Recovery: an international perspective. Epidemiolofia e Psychatria Sociale, 17, 2, pp128-137.

Turner, K., Lovell, K., \& Brooker, A. (2011) ... and they all loved happily ever after: 'recovery' or discovery of the self in personality disorder? Psychodynamic Practice, 17,3.

Wallcraft, J. (2005) The Place of Recovery: (In Mental Health at the Crossroads: The Promise of the Psychological Approach: Editors Ramon S. and Williams, J: Abingdon: Ashgate.)

Winnicott, D. (1965) The Maturational Process and the Facilitating Environment. London: Hogarth.

Zanarini, M. C., Frankenburg, F. R., Reich, D. B. \& Fitzmaurice, G. Attainment and stability of sustained symptomatic remission and recovery among patients with borderline personality disorder and axis II comparison subjects: a 16-year prospective follow-up study. Am J Psychiatry 169 pp 476-483. 
Table One

DEMOGRAPHICS AND OTHER CHARACTERISTICS OF SAMPLE OF SIXTY PARTICIPANTS

\begin{tabular}{|c|c|c|}
\hline Gender & Sample N (\%) & Haven Clients N (\%) \\
\hline Female & $47(78.3)$ & $123(74.1)$ \\
\hline Male & $13(21.7)$ & $43(25.9)$ \\
\hline Age & Sample N (\%) & Haven Clients N (\%) \\
\hline $18-20$ & $1(1.7)$ & $5(3.0)$ \\
\hline $21-24$ & $2(3.3)$ & $9(5.4)$ \\
\hline $25-34$ & $11(18.3)$ & $41(24.7)$ \\
\hline $35-44$ & $24(40.0)$ & $66(39.8)$ \\
\hline $45-54$ & $16(26.7)$ & $34(20.5)$ \\
\hline $55-65$ & $6(10.0)$ & $11(6.6)$ \\
\hline Ethnicity & Sample N (\%) & Haven Clients N (\%) \\
\hline White British & $57(95.0)$ & $156(94.0)$ \\
\hline British Born Pakistani & $1(1.7)$ & $2(1.2)$ \\
\hline Irish & $0(0.0)$ & $2(1.2)$ \\
\hline Irish/English & $0(0.0)$ & $1(6.0)$ \\
\hline Dutch & $1(1.7)$ & $1(6.0)$ \\
\hline German born Romany Gipsy & $0(0.0)$ & $1(6.0)$ \\
\hline Mixed race white/Afro Caribbean & $0(0.0)$ & $1(6.0)$ \\
\hline Mixed race white/Asian Indian & $0(0.0)$ & $1(6.0)$ \\
\hline White American - USA & $1(1.7)$ & $1(6.0)$ \\
\hline Some Life Circumstances & Female & Male \\
\hline Been in Care & 17 & 4 \\
\hline Forensic History & 9 & 10 \\
\hline Ever been employed & 23 & 9 \\
\hline In employment when came to Haven & 2 & 0 \\
\hline \multicolumn{3}{|c|}{ Reasons for Referral (in many cases more than one presenting problem) } \\
\hline Severe Depression/Anxiety & \multicolumn{2}{|c|}{139} \\
\hline Suicidal Impulses & \multicolumn{2}{|c|}{69} \\
\hline Self-harm & \multicolumn{2}{|c|}{59} \\
\hline Substance Misuse & \multicolumn{2}{|c|}{45} \\
\hline Antisocial/Violence/Aggression & \multicolumn{2}{|c|}{34} \\
\hline Isolation/Inter-personal problems & \multicolumn{2}{|c|}{30} \\
\hline Volatile Moods/mood swings & \multicolumn{2}{|c|}{28} \\
\hline Paranoia/Voices & \multicolumn{2}{|c|}{23} \\
\hline Eating Disorder & \multicolumn{2}{|c|}{18} \\
\hline Institutionalised long hospitalisation/prison & \multicolumn{2}{|c|}{6} \\
\hline Manic Episodes & \multicolumn{2}{|c|}{6} \\
\hline Obsessive Compulsive & \multicolumn{2}{|c|}{4} \\
\hline Gender Dysphoria/Gender Issues & \multicolumn{2}{|c|}{3} \\
\hline
\end{tabular}


Table Two

\begin{tabular}{|c|c|c|c|}
\hline $\begin{array}{l}\text { Service Area/ } \\
\text { Intervention }\end{array}$ & $\begin{array}{c}\text { Total Annual } \\
\text { Average } \\
\text { Over Two } \\
\text { Years Prior } \\
\text { to Haven* }\end{array}$ & $\begin{array}{c}\text { Annual } \\
\text { Service Use } \\
\text { Since } \\
\text { Attending } \\
\text { The Haven } \\
\end{array}$ & $\begin{array}{c}\text { Percentage } \\
\text { Reduction in } \\
\text { Use of } \\
\text { Service/ } \\
\text { Intervention }\end{array}$ \\
\hline Section 136 & 42.5 times & 18 times & $-57.64 \%$ \\
\hline Other Sections & 11 times & 4 times & $-63.63 \%$ \\
\hline Psychiatric In-patient Admissions & 55 times & 8 times & $-85.45 \%$ \\
\hline Use of Day Hospital & 32 clients & 14 clients & $-56.25 \%$ \\
\hline Use of Community MH Team & 36 clients & 14 clients & $-61.11 \%$ \\
\hline Use of NERIL (MH Help-line) & 1,264 times & 317 times & $-75.92 \%$ \\
\hline Use of Crisis Team & 187 times & 42 times & $-77.54 \%$ \\
\hline Criminal Justice MH Team & 0 & 0 & 0 \\
\hline Assertive Outreach & 0 & 0 & 0 \\
\hline Trust Eating Disorder Service & 56 times & 14 times & $-75.00 \%$ \\
\hline Psychology/Psychotherapy/Counselling & 30 clients & 21 clients & $-30.00 \%$ \\
\hline Annual Use of GP & 611 times & 459 times & $-24.87 \%$ \\
\hline Annual use of $\mathrm{A} \& \mathrm{E}$ & 141 times & 77 times & $-45.39 \%$ \\
\hline General Hospital Admissions & 47 times & 37 times & $-21.27 \%$ \\
\hline Police/Probation/Prison & 12.5 times & 2 times & $-84.00 \%$ \\
\hline Children's Social Services & 14 clients & 6 clients & $-57.14 \%$ \\
\hline Debt Agencies & 7 clients & 1 client & $-85.71 \%$ \\
\hline Housing/Homelessness & 11 clients & 2 clients & $-81.81 \%$ \\
\hline Substance Misuse Voluntary Agency & 4 clients & 1 client & $-75.00 \%$ \\
\hline Eating Disorder Voluntary Agency & 5 clients & 1 client & $-80.00 \%$ \\
\hline Mind Advocate & 39 clients & 11 clients & $-71.79 \%$ \\
\hline
\end{tabular}

* Column two represents a one year average of two year's use of the wider service area prior to The Haven e.g. 42.5 detentions under Section 136 mean a total of 85 sections for 50 clients over a two year period. 
Table Three

\begin{tabular}{|c|c|c|}
\hline \multicolumn{3}{|c|}{$\begin{array}{l}\text { MENTAL HEALTH TRUST ANALYSIS OF SERVICE USE } 2005 \text { TO } 2009 \\
\text { (Data Source: Care Base Date } 22^{\text {nd }} \text { June 2009) }\end{array}$} \\
\hline Service & $\begin{array}{c}\text { Two } \\
\text { year } \\
\text { average } \\
\text { before } \\
\text { Haven }\end{array}$ & $\begin{array}{c}\text { Four } \\
\text { year } \\
\text { average } \\
\text { after } \\
\text { Haven }\end{array}$ \\
\hline Number of Inpatient Spells & 111 & * \\
\hline Number of Section 136's & * & * \\
\hline Number of Other Sections & * & * \\
\hline Number of Attendances in Day Care Services & 2364 & 177 \\
\hline Number of Attendances in Outpatient Services & 370 & 39 \\
\hline Number of Attendances in CMHT Services (Community MH Team) & 1196 & 124 \\
\hline Number of Attendances in CRHT Services (Crisis Resolution \& Home Treatment) & 168 & * \\
\hline Number of Attendances in CJMHT Services (Criminal Justice MH Team) & * & * \\
\hline Number of Attendances in AO Services (Assertive Outreach) & 71 & $*$ \\
\hline Number of Attendances in Substance Misuse Services & $*$ & * \\
\hline Number of Attendances in Eating Disorder/Nutritional Advisor Services & 169 & $*$ \\
\hline Number of Attendances Psychology/Psychological/Counselling Services & 287 & $*$ \\
\hline Number of Attendances in Other Services & * & $*$ \\
\hline
\end{tabular}

* Any breakdown of data where the aggregated numbers are less than 30 , are not reported due to Patient Confidentiality as the Mental Health Trust considered certain patients would be able to be identified if the figures were low. 


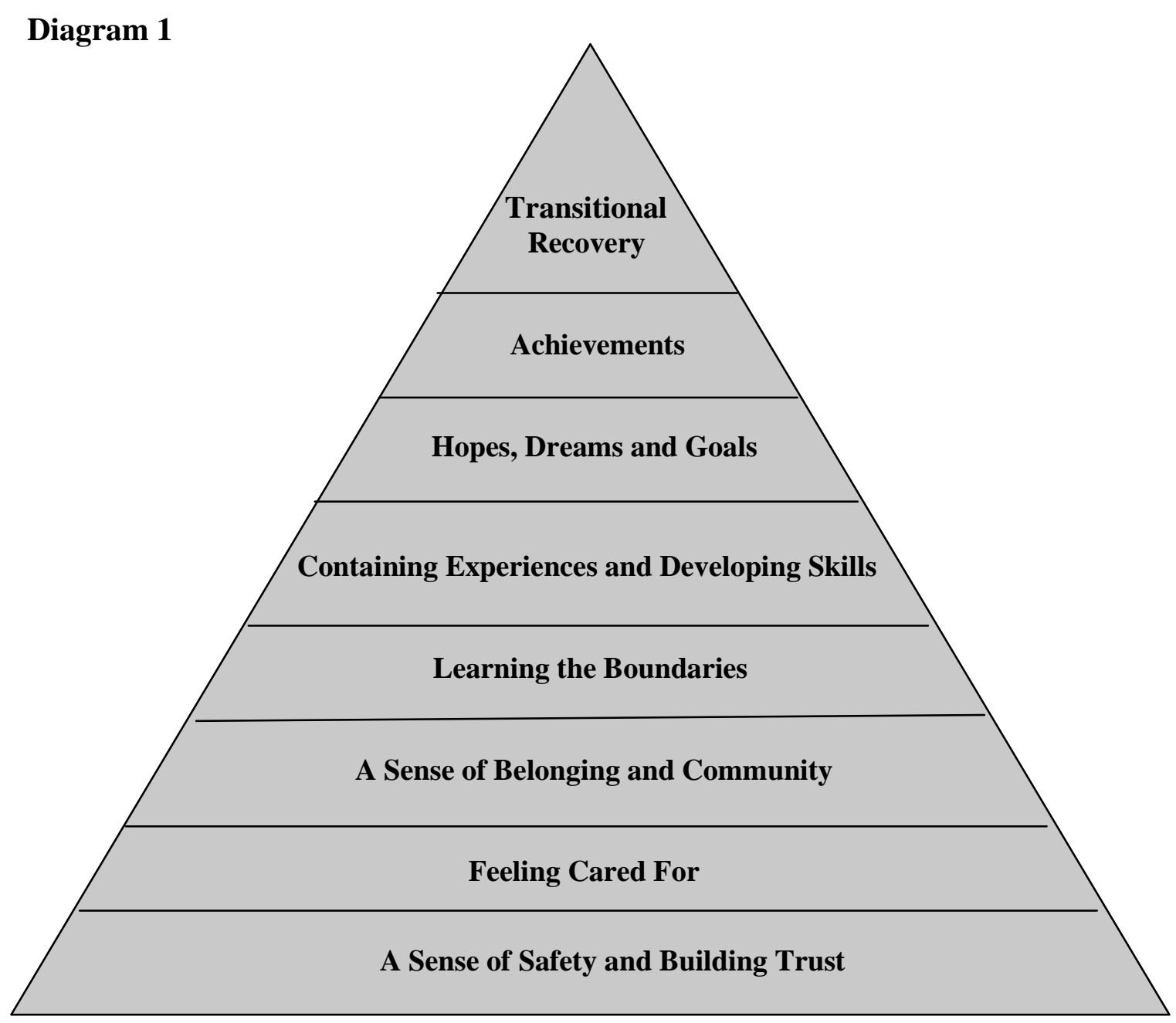

HAVEN HIERARCHY OF PROGRESS

The Journey of Recovery for Personality Disorder 